\title{
La feria comercial de arte como espacio de redistribución de capital simbólico: el caso

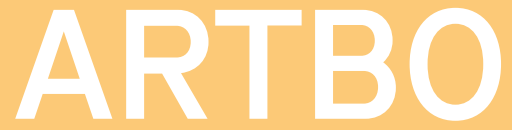

\section{Artículo de investigación}

\section{Leonardo Santana Viloria}

Universidad Jorge Tadeo Lozano, Colombia leonardo.santana@utadeo.edu.co

Recibido: 2 de mayo de 2018

Aprobado: 26 de julio de 2018

Cómo citar este artículo: Santana Viloria, Leonardo (2019). La feria comercial de arte como espacio de redistribución de capital simbólico: el caso ARTBO. Calle 14: revista de investigación en el campo del arte 14(25), pp. 72-85.. DOI: https://doi. org/10.14483/21450706.14049

\section{(c) (1)}

https://creativecommons.org/licenses/by/4.0/deed.es 



\section{Resumen}

En el presente trabajo se analiza el evento conocido como feria de arte y su papel en el circuito artístico, tomando como caso de estudio la Feria de Arte de Bogotá (ARTBO). Se examina su dimensión cultural desde la sociología de la cultura de Pierre Bourdieu y se contrasta la hipótesis de que la feria de arte es un nodo de redistribución de capital simbólico, mediante entrevistas a galeristas participantes. Los resultados confirman la hipótesis acerca del papel de la feria en la circulación contemporánea de bienes simbólicos.

\section{Palabras claves}

Feria de arte; mercado de arte; capital simbólico; ARTBO

The art fair as a space for the redistribution of symbolic capital: the ARTBO case

\section{Abstract}

This article analyzes the art fair and its role in the art world, taking as a case study the Bogota Art Fair (ARTBO). Its cultural dimension is examined from the view point of Pierre Bourdieu's sociology of culture. The hypothesis that the art fair is a node of redistribution of symbolic capital is confronted through interviews with participating gallerists. The results of this exercise point to the confirmation of our hypothesis about the role of the fair in the contemporary circulation of symbolic goods.

\section{Keywords}

Art fair; art market; symbolic capital; ARTBO

\section{Le Salon d'art en tant qu'espace de redistribution du capital symbolique: I'affaire ARTBO}

\section{Résumé}

Cet article analyse l'événement connu sous le nom de salon d'art et son rôle dans le monde artistique, en prenant pour exemple la Bogota Art Fair (ARTBO). Sa dimension culturelle est examinée du point de vue de la sociologie de la culture de Pierre Bourdieu. L'hypothèse selon laquelle la foire de l'art est un nœud de redistribution du capital symbolique est confrontée à travers des entretiens avec des galeristes participants. Les résultats suggèrent la confirmation de notre hypothèse sur le rôle de la foire dans la circulation contemporaine des biens symboliques.

\section{Mots clés}

Foire d'art ; marché de l'art ; capital symbolique ; ARTBO

\section{A feira de arte como espaço para a redistribuição do capital simbólico: o caso ARTBO}

\section{Resumo}

Este artigo analisa o evento conhecido como feira de arte e seu papel no circuito artístico, tendo como caso de estudo a Feira de Arte de Bogotá (ARTBO). Sua dimensão cultural é examinada a partir do ponto de vista da sociologia da cultura de Pierre Bourdieu. A hipótese de que a feira de arte é um nó de redistribuição simbólica de capital é confrontada por meio de entrevistas com galeristas participantes. Os resultados apontam para a confirmação de nossa hipótese sobre o papel da feira na circulação contemporânea de bens simbólicos.

\section{Palavras-chaves}

Feira de Artes; mercado de arte; capital simbólico; ARTBO 


\section{Maillallachiska}

Kai tsabaju kawachimi kai artikaskapi, kai iachaikuska kai arti kaska kai Bogota alpa suti kaskapi (ARTBO) chi tupurinchi kai kaugsaikuna Pierre Bourdieu.kai tsabaju.

Kagsinami kai artimi ka aidachinakuspa chasami paikuna aidanakurka chi tsabaju arti suti ka kawachinakuspa. Ña kai Tukui ruraska sug iuiarsi tiarka imasami kai arti kaskasina imasami kai punchaiatata kawachirii imasami iukari kai kawachikuna.

\section{Rimangapa Ministidukuna}

Arti suti kawachii Arti mirkadumi tiaska; kawachii kai arti; ARTBO 


\section{Introducción}

El mercado de arte colombiano ha presentado un gran crecimiento en los últimos quince años manifestado de varias formas: la creación y consolidación de espacios culturales que han aumentado tanto la producción y difusión del trabajo de los artistas nacionales como el acceso del público a este tipo de consumo cultural (bienales, salones, ferias); el aumento en el flujo de inversiones en este mercado mediante la apertura de galerías; la llegada de capital extranjero que invierte en arte nacional; y el aumento de obras de artistas colombianos presentes en subastas internacionales. Dentro de este auge ha tenido un papel importante la feria comercial, la cual consiste en un espacio de distribución del mercado, limitado a un lugar y momento específico, en donde se convocan y reúnen productores y consumidores. El objetivo de este tipo de eventos es el encuentro de una gran cantidad de agentes del circuito artístico (artistas, galeristas, coleccionistas, especuladores, público) que pueden descubrir obras y artistas de su preferencia y así generar transacciones.

Con el presente artículo se busca reflexionar sobre el papel que tiene esta clase de eventos dentro del circuito de arte y la relación que estos espacios tienen con los circuitos artísticos a partir de sus particularidades económicas. Para tal fin, se analiza como caso de estudio la Feria Internacional de Arte de Bogotá (ARTBO) y su interacción con el circuito artístico. Para ello se plantea la siguiente hipótesis: la feria de arte es un nodo ${ }^{1}$ dentro del circuito artístico que redistribuye el capital simbólico entre los diversos agentes: artistas, galerías, representantes, críticos y demás. Esta hipótesis muestra cómo el término "posicionamiento" se refiere al aumento de capital simbólico y cómo la feria de arte es nodo para que artistas, galeristas, la ciudad y la feria misma puedan enriquecerse del mismo en términos de capital simbólico y capital económico. La contrastación de esta hipótesis se hace mediante el análisis del marco teórico y la aplicación de entrevistas a los galeristas participantes.

En la primera parte, se presenta una revisión de los orígenes de la feria de arte; en la segunda, se reflexiona

1 Rossi (1993) utiliza el término nodo para caracterizar el "hecho urbano" entendido como un elemento en la ciudad que sirve como catalizador para cambiar la configuración urbana. De forma similar aquí se usa el término nodo para caracterizar eventos (como la feria de arte) que actúan como catalizadores de transformación de todo el sistema del circuito artístico. sobre el papel de la feria en la redistribución de capital simbólico; la tercera parte presenta la Feria de Arte de Bogotá (ARTBO) y la cuarta muestra los resultados de las entrevistas y se hace un análisis de estos resultados en el contexto del papel de ARTBO en el circuito artístico nacional. Finalmente se presentan algunas conclusiones.

\section{Orígenes de la feria de arte}

La feria de arte ha adquirido el estatus de corazón del mercado de arte internacional durante la época contemporánea. Autores como Barragán (2008) y Morgner (2014a), dan cuenta de su papel central al referenciar el siglo XXI como "la era de la feria de arte" debido al aumento de este tipo de eventos a partir de finales de los años 90. La analogía con el corazón es adecuada, ya que su papel fundamental es impulsar el número de transacciones del mercado durante un lugar y tiempo determinados, además de servir de nodo central para la creación y fortalecimiento de lazos entre distintos agentes del circuito (Morgner, 2014b).

Los orígenes de la feria de arte se remontan a las festividades religiosas que exigían peregrinaciones a un centro de culto: el desplazamiento de personas desde lugares remotos a estos centros con el fin de honrar a una deidad. Walford (1883) da ejemplos de tales desplazamientos en la Grecia clásica durante el siglo VIII a.e.c. (como los juegos olímpicos); Tiro en el siglo VI a.e.c.; Roma durante la República y el Imperio (siglos VI a.e.c a $V$ e.c.); Italia en el siglo $V$ e.c.; y Alemania durante el reinado de Carlomagno (siglo IX e.c.). De hecho, la palabra feriae en latín significa festividad. El hecho de que se dieran las movilizaciones de personas desde la periferia a los lugares de peregrinación dio lugar a la creación de elementos comerciales y de un turismo incipiente. Por un lado, los peregrinos debían abastecerse y encontrar lugares de descanso; por otro, traían desde sus regiones bienes autóctonos que podían vender durante el viaje y en el lugar de la festividad. De esta forma la festividad religiosa se fue transformando en una feria artesanal al crearse, por ejemplo, casas especiales para la presentación y venta de objetos desconocidos que traían los peregrinos (Morgner, 2014a). Estas ferias comerciales reunían en determinadas fechas a productores que llevaban sus bienes para la venta. Los comerciantes encontraron varias ventajas de la participación en estas ferias artesanales: la posibilidad de encuentro entre oferentes y demandantes de los artículos; la existencia de un esquema de seguridad para 


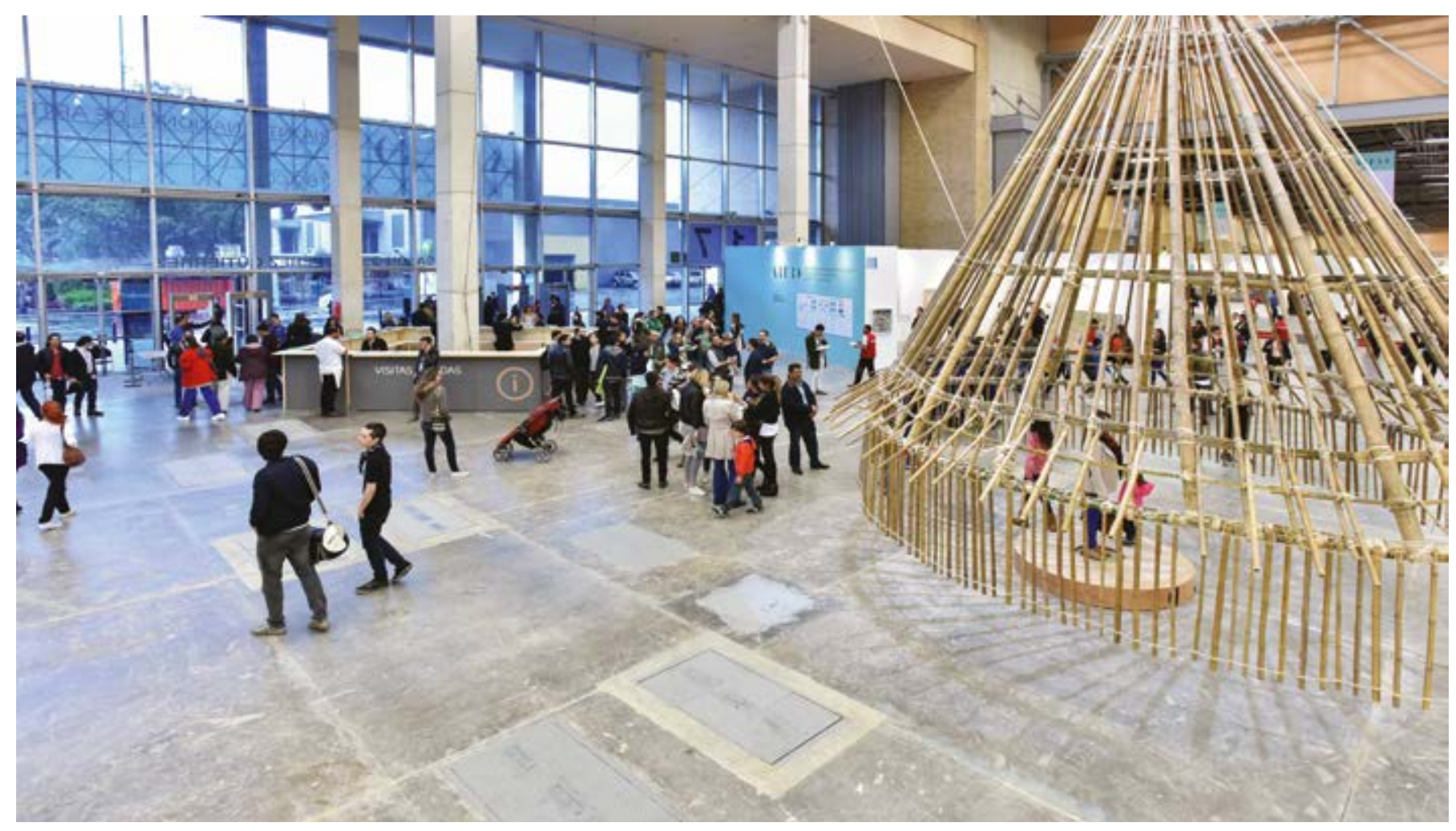

Imagen 1. La sección Sitio es un espacio de grandes instalaciones. Este módulo le da un marco al espacio de la feria, pues la instalación de gran formato es la bienvenida a los visitantes. Cónica. Tania Candiani (2016). Imagen cortesía de la Cámara de Comercio de Bogotá.

los viajeros que era provisto por los señores feudales; y la incorporación de una política de cumplimiento de los acuerdos y transacciones realizadas en la feria. El surgimiento de estas instituciones alrededor del evento ferial fue la semilla no solo de la feria de arte, sino de otras organizaciones económicas como la bolsa de valores.

Ciertos elementos de la feria religiosa subsisten en la feria de arte. En palabras de Morgner "El evento religioso no solo proveía una estructura sobre la cual se podían desarrollar negocios, sino que traía un simbolismo religioso a estos mismos negocios" (2014a, p. 322), lo cual se aplica al espíritu de la feria de arte. Las festividades religiosas congregaban multitudes en torno a la creencia: creencia en la bondad de la divinidad, la efectividad del culto y la necesidad de asistencia al evento para conseguir los favores del dios. Thornton, señala cómo la creencia y el culto se ha desplazado al arte. "Soy ateo, pero creo en el arte. Voy a las galerías como mi madre va a la iglesia. Esto me ayuda a entender el modo en que vivo" (2008, p. 35).

La feria artesanal dio paso a la feria industrial durante los siglos XVII y XVIII. La mejora en la comunicación y la estandarización de productos hicieron obsoleto el transporte de gran cantidad de artículos heterogéneos dando paso a un esquema ferial de presentación de novedades, como las ferias mundiales o exposiciones universales. Durante este período también surgieron los salones de arte organizados por las academias europeas y que fueron replicados más tarde en todo el mundo.

La transición del esquema artesanal al industrial fue acompañada del surgimiento de la figura del dealer, intermediario entre oferentes y demandantes de artículos que antes eran intercambiados directamente en las ferias artesanales, pero ahora era más difícil transar de primera mano debido al tamaño de la producción en masa. Amberes, fue la ciudad donde inició el trabajo de estos intermediarios durante el siglo XVI, mientras las formas de producción y comercio industrial iban tomando forma. Se crearon las primeras galerías (Schilderspanden) al tiempo que los temas abordados por la pintura, paisajes y escenas cotidianas tenían un público masivo. Los dealers, buscaban clientes para las obras almacenadas en las primeras galerías y proveían también financiamiento para tales compras.

Los centros de mayor movimiento en el mercado del arte como Nueva York, París y Londres desarrollaron una red de dealers muy activa que conectaba galerías con el coleccionismo desarrollado sobre todo desde 
inicios del siglo XX. Otros lugares, donde no se concentraba tanto la actividad del mercado, como Alemania y Suiza crearon las primeras ferias de arte, siendo el primer referente Art Cologne en Colonia, en 1967. Dado que esta feria se enfocaba en el mercado alemán, se creó en 1970, Art Basel en Basilea, feria que buscaba convocar también coleccionistas internacionales. En ambas ferias participaban dealers exclusivamente, pues no podían participar casas de subastas o artistas directamente, que presentaban pinturas, esculturas y también joyería (Morgner, 2014a).

\section{La feria de arte como espacio de redistribución de capital simbólico}

La característica más relevante del mercado de arte es la particularidad del bien transado. El valor de la obra de arte es completamente crediticio: es un valor socialmente construido y, de acuerdo con Bourdieu (1995), está asociado a la producción de fe. El valor de una obra se construye mediante las interacciones del circuito: marchantes, críticos, curadores y artistas poseen el capital simbólico necesario para ser vertido en una obra. La credibilidad en el crítico, por ejemplo, se traspasa a la obra que es bendecida por él. Bourdieu (1979), también desarrolla los conceptos de capital económico, capital social y capital cultural con el fin de explicar las dinámicas sociales: el primero hace referencia a la acumulación de recursos financieros por parte de una persona o institución y a la riqueza disponible para ser usada en función del consumo; el segundo, a la posición dentro de la estructura de clases sociales, la distinción que proyecta un sujeto y su capacidad de generar relaciones con otros agentes; y el tercero, al conocimiento, habilidades, destrezas y educación acumuladas por las personas. La acumulación de estos capitales determina la posición de un agente (persona o institución) dentro de lo que el mismo autor llama campo: un espacio de interacción social y de relaciones entre estos agentes de acuerdo con su posición. El campo no es un estado estático, pues continuamente fluyen estos capitales en su interior y generan cambios en las posiciones de los agentes.

Junto con los tres capitales mencionados, Bourdieu introduce también la noción de capital simbólico y bienes simbólicos: “El capital simbólico es cualquier propiedad (cualquier tipo de capital, físico, económico, cultural, social) cuando es percibida por agentes sociales cuyas categorías de percepción son de tal naturaleza que les permiten conocerla (distinguirla) y reconocerla, conferirle algún valor" (Bourdieu, 1997, pp. 107-108). El capital simbólico es, por tanto, una cualidad del capital que permite que los agentes le den un valor y distinción al agente poseedor de dicho capital. Por tanto, términos como "posicionamiento" y "reconocimiento" hacen referencia a la cantidad de capital simbólico presente en el capital económico, social o cultural de un agente. Los bienes simbólicos, son aquellos objetos dotados del reconocimiento y distinción necesarios para conferirles valor. Estos bienes simbólicos pueden transarse en mercados económicos, como es el caso del mercado de obras de arte. En el mercado de bienes simbólicos en el campo del arte, este autor plantea la

(...) coexistencia antagónica de dos modos de producción y de circulación que obedecen a lógicas inversas. En un polo, la economía 'anti-económica' del arte puro que, basada en el reconocimiento obligado de los valores del desinterés (...) está orientada a la acumulación de capital simbólico (...) En el otro polo la lógica 'económica' de las industrias literarias y artísticas (...)

Una empresa está tanto más cerca del polo 'comercial' cuanto más directa o más completamente los productos que oferta en el mercado responden a una demanda preexistente, y dentro de unas formas preestablecidas. (Bourdieu, 1995, pp. 214-215)

Estos dos modos de producción son descritos como de corto y largo plazo por el autor. En el corto plazo funciona la lógica económica o de rentabilidad, en la que se intercambian productos de artistas posicionados en el campo artístico. En el largo plazo, las industrias culturales se acercan a la lógica del arte puro, apostando por artistas no posicionados, pero con potencial.

La dinámica entre ambos polos se da dentro del campo del arte. En este campo se presenta la "producción de la creencia", o la producción de la illusio, que es simplemente la adhesión al juego jugado en el campo artístico: "el artista que hace la obra está hecho a su vez, en el seno del campo de producción, por todo el conjunto de aquellos que contribuyen a descubrirlo y a consagrarlo como artista conocido y reconocido: críticos, prologuistas, marchantes" (p. 253). Es decir, el posicionamiento de un artista nuevo depende de su posición en el campo, de la forma como críticos, revistas especializadas, bienales, concursos y demás espacios de interacción del campo artístico lo posicionen. 
Esta producción de la creencia es producción de capital simbólico en la figura del artista, más cercano al polo del arte puro. Una vez tal artista es reconocido y admirado entra al polo 'comercial' de corto plazo, donde ese capital simbólico puede convertirse en capital económico. La interacción entre capital simbólico y económico es continua. Ambos capitales se mueven en el tiempo en la medida que el juego dentro del campo presenta cambios de posiciones. Además

(...) el capital económico sólo puede proporcionar los beneficios específicos ofrecidos por el campo si se reconvierte en capital simbólico. La única acumulación legítima (...) consiste en hacerse un nombre, un nombre conocido y reconocido, capital de consagración que implica un poder de consagrar objetos (es el efecto de marca o firma) o personas (mediante la publicación, la exposición, etc.). (Bourdieu, 1995, p. 224)

Lo anterior, señala como el valor económico de la obra de arte (su precio) está en función del capital simbólico acumulado ¿Cuál es, entonces, el papel de la feria de arte dentro de la circulación, acumulación y distribución de esta forma de capital? La feria es una plataforma pública para la redistribución de la reputación:

La reunión de galerías atrae a los medios, pero también a profesionales del arte, como curadores, directores de museos y coleccionistas (...) El público de la feria no es una masa que permanece desconocida como el público de los medios masivos, sino que participa y es creada por medio de la interacción (...).

Un perfil especial es elaborado dentro de una red de galerías, bien sea estando presente o estando próxima a ellas. Algunas galerías pueden unirse para tener un trabajo conjunto, como pares iguales, mientras otras pueden querer localizarse cerca de las más prestigiosas. De esta forma las galerías secuestran la reputación de otras y así confirman su estatus o crean una reputación desarrollando una voz más significativa a través de una gran densidad de galerías amigas. (Morgner, 2014b, p. 40)

Es por tanto la feria de arte un nodo de encuentro y distribución de capital simbólico que puede ser convertido con el tiempo en capital económico. Es un proceso de continua relegitimación. Esto explica la explosión de ferias de arte en el mundo a partir de finales del siglo XX. Al cambiar el mercado del arte luego de las caídas de las burbujas financieras de finales de los años 90 y principios del siglo XXI, que alimentaban a un grupo de coleccionistas con vastos recursos para demandar arte a través de casas de subastas, se requiere de nodos que dinamicen la circulación del capital simbólico (el cual es el "verdadero bien" transado en el mercado económico artístico). De la misma forma que los capitales financieros durante los últimos 100 años de globalización, han encontrado en las nuevas tecnologías y los procesos desregulatorios elementos que permiten aumentar la velocidad de su circulación a nivel mundial, la feria de arte es la "nueva tecnología blanda" que permite en días o semanas un encuentro de todos los agentes del circuito y una redistribución del capital simbólico.

El capital simbólico no está presente en las obras, sino en los artistas, en las galerías, en los críticos que las juzgan, en los jurados de los premios, en los eventos. Baudrillard (2002), señala cómo la firma del creador reviste de singularidad a la obra. Podríamos decir que la obra no lleva una sola firma, lleva múltiples rúbricas. La obra lleva el capital simbólico acumulado por el artista, pero también el capital simbólico de los críticos que han escrito sobre la trayectoria del mismo. $Y$ el capital simbólico de la galería que ha patrocinado al artista. Cuando estos elementos se encuentran en la feria de arte, lo de menos es el capital económico, las ventas y los ingresos. El balance que hace la galería participante es si aumentó o disminuyó su capital simbólico y el de los artistas que representa.

La estrategia que la galería tiene frente a este proceso implica actuar en dos movimientos: inserción a redes y posicionamiento. Morgner (2014b) resalta el papel central de la feria de arte contemporánea como creadora y fortalecedora de redes entre los agentes del circuito. Este autor señala tres funciones que cumple la feria:

- Vincula artistas, dealers, profesionales y coleccionistas de distintas regiones.

- Permite la mutua observación entre estos agentes.

- Forma vínculos: ventas, presentación de nuevos artistas incorporados al circuito, entre otros.

La posibilidad de crear una red es potestad de la feria, mientras que el objetivo de la galería es la inserción en la misma. La capacidad de insertarse en la red, así como su ubicación y papel dentro de ella, depende del posicionamiento: "la manera en que los consumidores, usuarios, compradores y otros aprecian marcas competidoras o tipos de productos" (Barragán, 2008, p. 34). Artistas, galerías y ferias compiten por "conquistar una posición" dentro del campo del circuito del arte. 


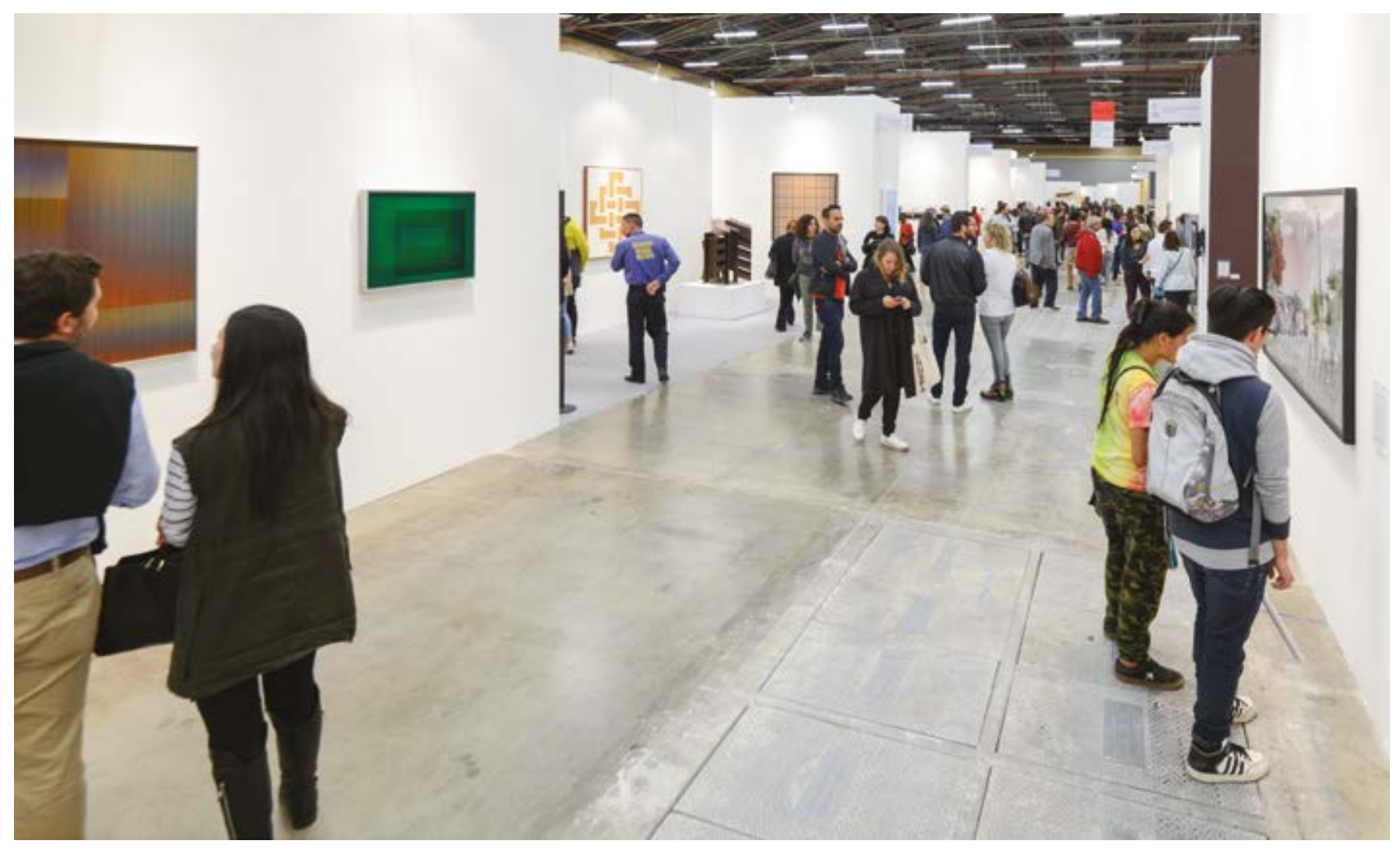

Imagen 2. Sección Principal: Espacio de exposición de las galerías y recorrido de visitantes. Imagen cortesía de la Cámara de Comercio de Bogotá.

El producto final del capital simbólico en la estrategia de posicionamiento es el branding, la construcción de una marca (Barragán, 2008). El posicionar un artista, una galería o una feria es uno de los principales objetivos dentro del circuito del arte. De esta forma el artista, la galería y la feria son sinónimo de calidad y se convierten en sí mismos en una marca. Baudrillard señala el "valor mítico que toma esa garantía de origen que es la firma (...) Ella es la que dice lo que la obra significa: el gesto del artista que se materializa en ella" (Baudrillard, 2002, p. 112). La firma del artista es el signo de su marca y esta marca es el signo del capital simbólico en la obra.

El intercambio de capital simbólico entre galerías se da en un contexto de competencia entre ellas dentro de la feria de arte. Tal competencia tiene el objetivo de ganar el favor del público, entendiendo este como el segmento del circuito del arte que realiza la recepción de las obras y juzga su valor. Simmel (1991) señala como la feria de arte crea un espacio adecuado para realizar tal valoración a través de la comparación de una gran cantidad de obras en el mismo lugar. El valor de la obra es relativo a los movimientos, tendencias y líneas de trabajo del resto del mercado artístico. Y es aquí, donde otra función de la feria es la de convertir el capital simbólico en económico a través de la determinación de los precios. La feria de arte permite la construcción mediante la misma comparación e interacción que redistribuye capital simbólico entre galerías, artistas y demás actores del circuito. Además, permite medir el valor artístico de la obra mediante la comparación con el conjunto de las demás obras expuestas y convertir este valor simbólico en precio. Obsérvese cómo la determinación del precio, y los aspectos económicos que esto conlleva como los ingresos para las galerías y sus proyecciones de rentabilidad, es el último paso en el proceso descrito (Redistribución del capital simbólico, luego conversión del capital simbólico a valor artístico de la obra y, finalmente, determinación de su valor económico como precio).

\section{La Feria de Arte de Bogotá (ARTBO)}

La Feria Internacional de Arte de Bogotá fue creada en 2004 por la Cámara de Comercio de Bogotá. Se realiza desde entonces, todos los años en el mes de octubre, en el Centro Internacional de Negocios y Exposiciones (Corferias) en Bogotá. La feria reúne durante cuatro días a galerías colombianas y extranjeras, las cuales cuentan con un espacio dentro del recinto ferial para la exposición de sus artistas y obras. En su primera edición 


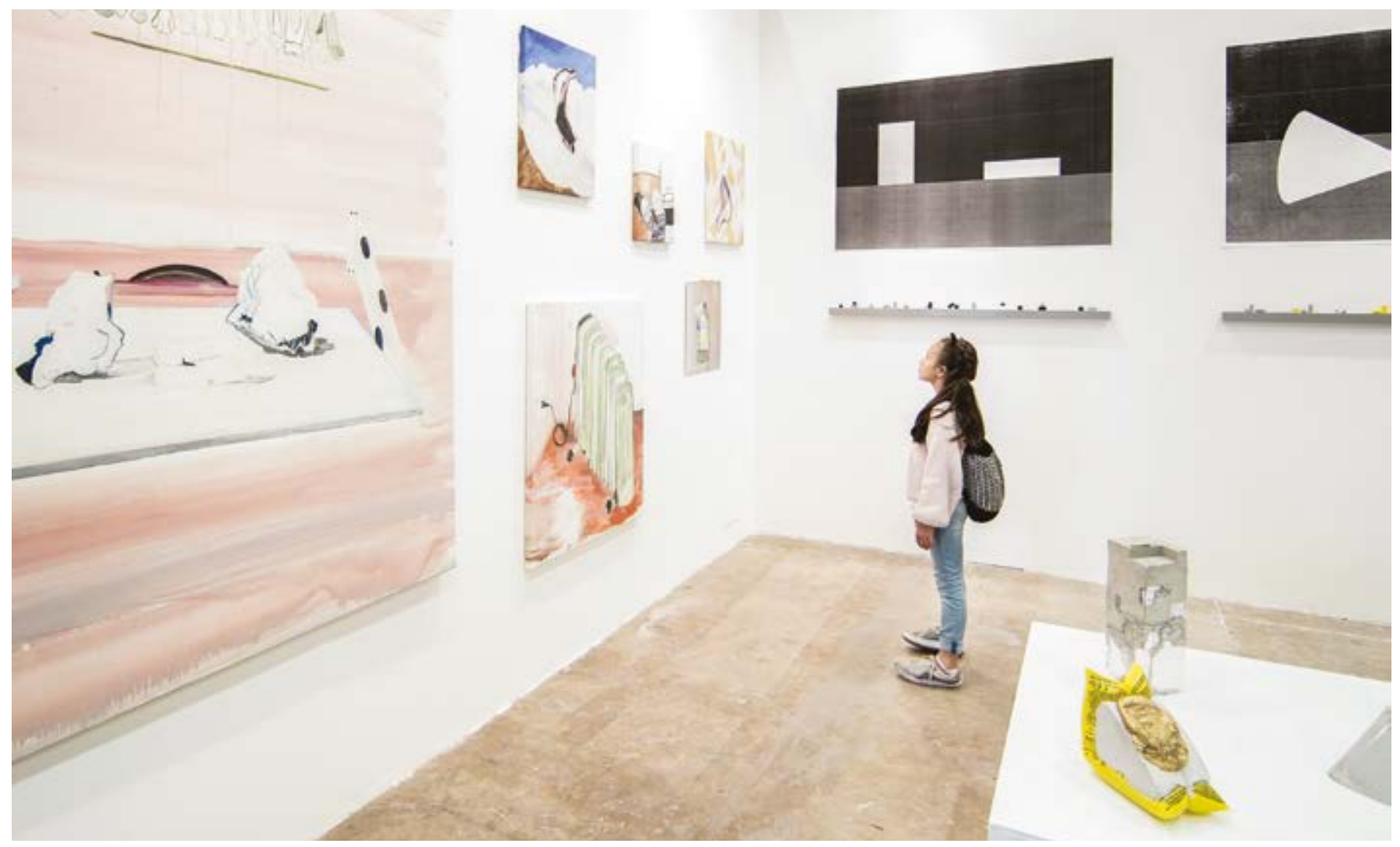

Imagen 3. ARTBO. Feria Internacional de Arte de Bogotá (2018). Imagen cortesía de la Cámara de Comercio de Bogotá.

contó con 14 galerías nacionales y 15 extranjeras, mientras que en 2016 estos números habían crecido a 74 galerías en total (ARTBO, 2017). Esto refleja el éxito del evento en términos de su convocatoria y crecimiento.

La feria contiene otros espacios y proyectos además de su sección principal comercial de galerías. Artecámara, es un salón de arte presente desde la primera edición y que consiste en la convocatoria de artistas jóvenes a que presenten sus obras, las cuales son seleccionadas y organizadas por un curador elegido cada año por la organización de ARTBO (Salamanca, 2015). En 2016 participaron 24 artistas jóvenes en Artecámara.

\section{Otras secciones de ARTBO son:}

- Proyectos: Esta sección muestra obras o instalaciones de artistas que cuentan con la representación de una galería y que son seleccionados por un curador. El curador, toma prestadas estas obras de las galerías con el fin de establecer una exposición independiente en lo que Bankowsky ha denominado "Art Fair Art". Este tipo de sección está presente en las principales ferias de arte: en 2007, en la feria CIRCA Puerto Rico, "cada día un curador invitado se pasea por la feria y concibe una exposición temática utilizando las obras colgadas en las galerías participantes (...) se piden las obras prestadas a las galerías, y se cuelgan en los booths dispuestos para ellos tal como si se tratara de una exposición de cubo blanco" (Barragán, 2008, p. 53). Esta es la dinámica del curador invitado, con el objetivo de que la feria traspase el espacio de encuentro comercial y genere una narrativa, alterna pero independiente. Tal espacio es parte del esquema modular de la feria: pretende ser el módulo más cercano a las expresiones museísticas o de bienal.

- Referentes: al igual que la sección anterior, curadores invitados toman obras de las galerías, en este caso buscando artistas referentes de la historia del arte latinoamericano en diversos ejes curatoriales definidos previamente.

- Sitio: espacio de grandes instalaciones con uno, dos o tres artistas invitados. Este módulo le da un marco al espacio de la feria, pues la instalación de gran formato es la bienvenida a los visitantes.

- Foro: Espacio de charlas y conferencias.

- Libro de artista: curaduría de obras editoriales (libros y demás publicaciones) sobre arte. Traslapada con una feria del libro, esta sección pretende la promoción comercial de este tipo de productos con 2 editoriales principales y 16 secundarias en la última versión de la feria. 
- Articularte: espacio de interacción del público mediante talleres y laboratorios.

\section{Resultados de entrevistas a galeristas}

Con el fin de contrastar el papel asignado a la feria de arte en la literatura presentada se entrevistó a los representantes de seis galerías participantes en ARTBO con el siguiente cuestionario abierto:

- ¿Considera que la Feria de Arte de Bogotá (ARTBO) ha ayudado a su galería en la creación y fortalecimiento de redes con otras galerías, coleccionistas y el mercado del arte en general?

- ¿Cuál ha sido el principal criterio de su galería para la selección de obras y artistas presentados en ARTBO 2016?

- ¿Cuál considera que es el elemento diferenciador de ARTBO frente a otras ferias de arte del continente?

- ¿Cuáles considera que son las galerías y artistas más prestigiosos presentes en ARTBO 2016?

Se envió este cuestionario vía correo electrónico. Los resultados muestran cómo el principal objetivo de los galeristas en la participación de la feria no es la generación de ventas, sino el posicionamiento. Los galeristas entrevistados expresan: "vemos exponencialmente como la participación en ferias como ARTBO ha contribuido a desarrollar una red de contactos en América Latina." "E "El principal objetivo de participación en la feria es el posicionamiento de la galería"3 "Frente a este objetivo, las ventas pasan a un segundo plano." ${ }^{4}$ No se trata únicamente de la generación de contactos como señala Morgner (2014b), sino de la posición de cada agente en el campo de la red. Luego de la feria, los galeristas esperan que las posiciones en ese campo hayan sido modificadas en favor propio. Se escogen artistas que "sean comerciales, pero con un alto contenido de información y belleza en el montaje. Además, que sean chilenos para crear la marca Chile en el arte internacional." ${ }^{5} \mathrm{El}$ posicionamiento en el campo no solo es para un determinado artista o galería, sino también para una ciudad o país: el City Marketing y Country

2 Entrevista por correo electrónico a Juan Eyheremendy.

Galería Vermelho. 25 de noviembre de 2016.

3 Entrevista telefónica a Liliana Hernández. Galería Plecto.

19 de noviembre de 2016.

4 Entrevista telefónica a Angélica Fajardo. Galería El Museo.

18 de noviembre de 2016.

5 Entrevista por correo electrónico a Irene Abujatum.

Galería AFA. 21 de enero de 2017
Branding se juegan en el mismo espacio. De esta forma, Angélica Fajardo de la galería El Museo señala como "ARTBO es la principal plataforma del país y corazón de la Semana del Arte que se realiza con las ferias paralelas en el Distrito de Arte de Bogotá."

El objetivo primario de posicionamiento es compatible con la mutua observación entre competidores y la formación de precios, sin embargo, estos dos últimos no son los objetivos de la participación en la feria. Liliana Hernández, de La Galería Plecto, señala que la indagación por precios no se realiza "directamente ya que no se presentan tasadores. Para esta comparación se requiere de una dinámica más orgánica para averiguar precios y monedas", haciendo referencia a una dinámica posterior a la realización de la feria donde se procese la información económica adquirida en el evento.

Como señala Bourdieu (1995) una industria cultural "que entra en la fase de explotación del capital simbólico acumulado hace que coexistan dos economías diferentes, una orientada hacia la producción y la investigación, (...) la otra orientada hacia la explotación del fondo y la difusión de los productos consagrados" ( $p$. 219). Nuevamente se muestra como estas dos economías están presentes en los artistas que se presentan en la feria: "Mientras que otras galerías se enfocan en los artistas consolidados, Plecto muestra los de carrera intermedia en vía de consolidación (45-50 años) al igual que propuestas de artistas jóvenes (20-25 años)."

También, Juan Eyheremendy, de la galería Vermelho, expresa que "Intentamos siempre seleccionar artistas que ya son conocidos por el público de la feria, con artistas que aún no son tan conocidos". De la misma forma que la galería intenta posicionar su marca y la de su ciudad, aprovecha la feria para posicionar sus artistas. Es esta la razón por la que las dos economías señaladas por Bourdieu conviven en la feria: artistas consolidados que hacen parte del fondo de capital simbólico y económico que pueden revertir su capital en artistas nuevos. El que una galería se convierta en referente es un aumento del capital simbólico que se traspasa a sus artistas nuevos. De esta forma, se puede señalar que ciertos galeristas son los más representativos de la feria: "el stand de León Tovar Gallery para el mercado secundario; Sicardi Gallery en Houston, entre cuyos artistas está Miguel Ángel Rojas; La Cometa; Nueveochenta con el artista John Castles; Galería Luisa Strina con el artista Jorge Macchi; Galería Elba Benítez con el artista Carlos Bunga; Galería Eduardo Fernandes con la artista Luz Ángela Lizarazo; y la misma Plecto 


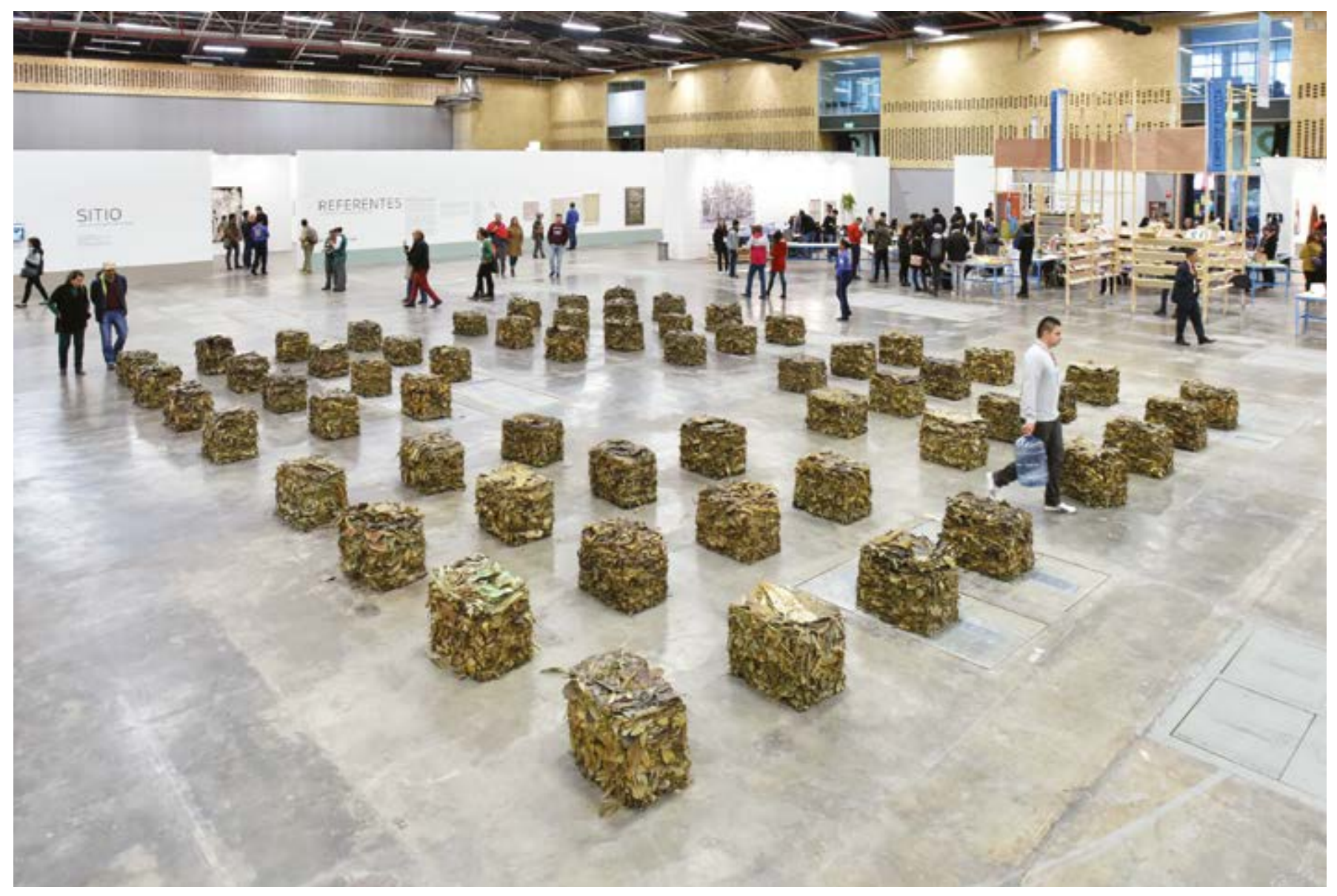

Imagen 4. Sección Sitio. Sin Título (Ladrillos de hojas). Juan Fernando Herrán. (1987-2016). Imagen cortesía de la Cámara de Comercio de Bogotá.

con los artistas Mario Vélez y Rafael Gómez Barros" dice Liliana Hernández.

Este juego del galerista con artistas consagrados y nuevos se presenta por las "dos representaciones opuestas de la actividad (...) mero comerciante o audaz descubridor" (Bourdieu, 1995, p. 223). La galería El Museo expresa bien esta mezcla: "También se desea mostrar obras inéditas de artistas consagrados como Nadín Ospina, Débora Arango, Álvaro Barrios o Carlos Rojas mezcladas con artistas emergentes como Sebastián Dávila, de poca exposición". Lo anterior con el objetivo de que los artistas consagrados permitan presentar a artistas noveles, mezclando las diversas economías culturales señaladas por Bourdieu y presentadas anteriormente.

La misma feria también se juega su posicionamiento con respecto a otras ferias ya que "el mercado es cada vez más agresivo y las ferias necesitan un posicionamiento meridiano para poder existir en la mente del coleccionista. El exotismo y el clima son elementos que contribuyen a forjar un posicionamiento" (Barragan, 2008, p. 36). Los entrevistados resaltan como ARTBO es una "feria muy especializada en lo latinoamericano, con una selección homogénea y con buena calidad de público" $^{6}$ y que "Colombia está muy cerca de los mercados más fuertes del arte, como Estados Unidos y México. Su ubicación es un factor diferenciador para postular a ella" según Irene Abujatum de la Galería AFA.

El "posicionamiento" de los agentes se refiere a su posición en el campo, por esto términos como "cerca" o "ubicación" son relevantes para el evento. Se trata de lograr la mejor ubicación en el circuito artístico para poder acumular capital simbólico gracias al flujo del mismo en la feria. Los participantes se encuentran y se evalúan durante el evento para luego reconfigurar las posiciones del campo y la posición de la misma ARTBO en comparación con otras ferias. Por esto, el éxito de una feria está determinado en la cantidad de capital

6 Respuestas remitidas por el Departamento de información de la Galería Alarcón Criado. 19 de noviembre de 2016. 


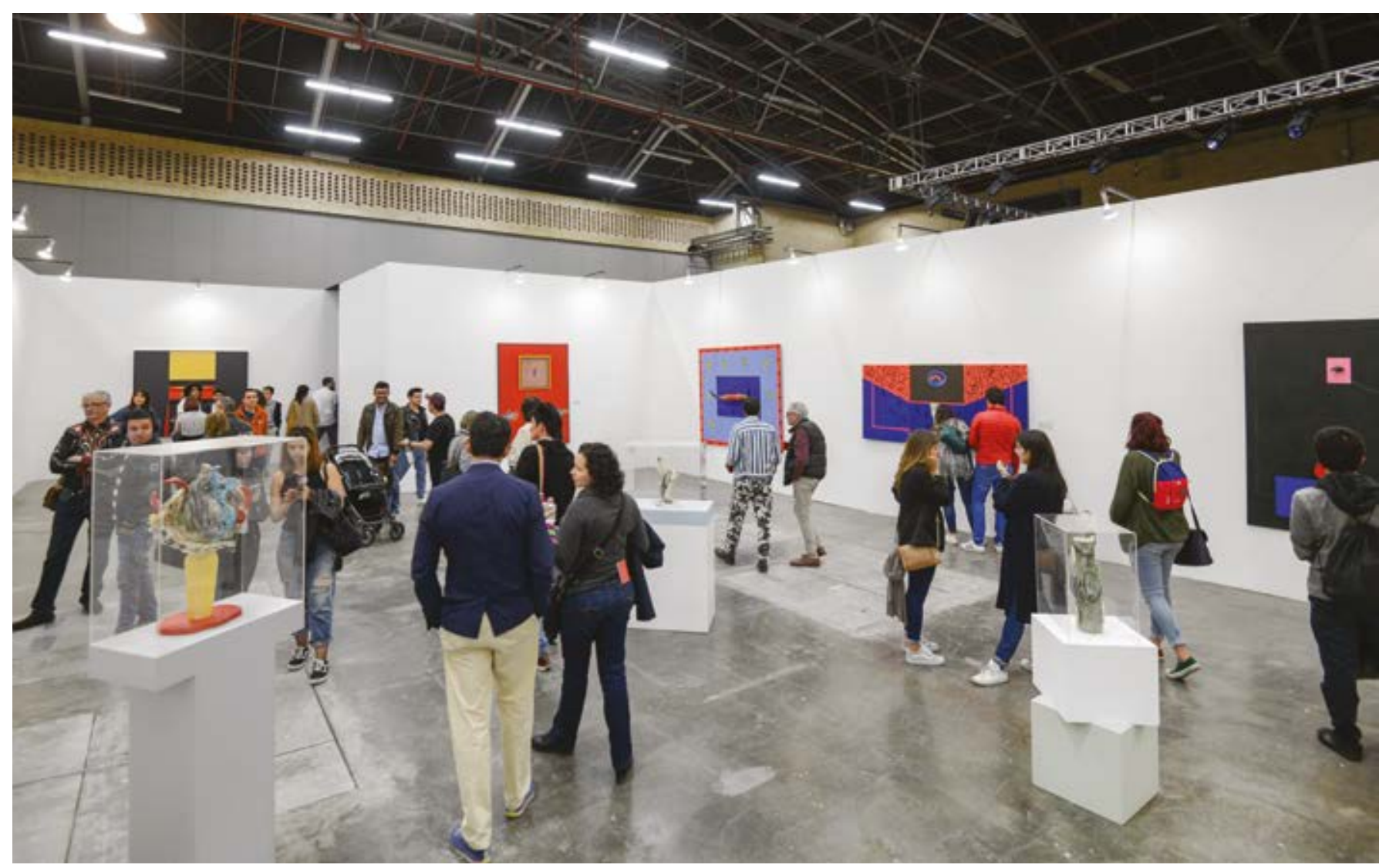

Imagen 5. ARTBO. Feria Internacional de Arte de Bogotá (2018). Imagen cortesía de la Cámara de Comercio de Bogotá.

simbólico que pueden acumular para sí misma y revertir en sus galerías y estas en sus artistas.

Esta lluvia de capital de arriba hacia abajo, también funciona en sentido contrario: la presencia de artistas referentes, y especialmente de curadores invitados, puede aumentar el capital simbólico de la feria misma. Por esto se señala un flujo de capital simbólico donde la feria de arte actúa como dinamizador para reconfigurar su acumulación y la posición de los agentes participantes en el campo del circuito del arte luego de concluido el evento. La heteronomía de un agente participante es mayor en la medida que dependa más de la red intrincada en el circuito y de este tipo de dinamizadores.

\section{Conclusiones}

La presente investigación utiliza los conceptos, acuñados por Bourdieu, de campo como espacio de interacción social, y de capital simbólico como reconocimiento de los participantes dentro de ese campo, y los desarrolla en el mercado del arte. De esta forma, muestra cómo ARTBO cumple un papel de nodo y catalizador que redistribuye ese capital simbólico entre obras, artistas, galeristas y galerías mediante la interacción y mutua observación de los agentes. Este capital simbólico además es reconvertido a capital económico, pues el valor monetario de la obra de arte es determinado por el reconocimiento de los agentes del circuito que rodean la obra: artista, galería, representantes, críticos y demás.

La firma del artista materializa este capital simbólico, el cual es dinámico pues constantemente la interacción de los agentes desplaza las posiciones de los mismos en el campo. Dado que hay una reconversión constante del capital simbólico en económico, la feria de arte cumple su papel comercial más allá de las ventas e ingresos derivados de la misma.

Al consultar a los galeristas participantes en ARTBO se confirma esta hipótesis, pues los entrevistados expresan la necesidad de posicionar nuevos artistas y explotar el nombre y reconocimiento de artistas consolidados (lo que Bourdieu llama doble economía en las reglas del arte). Esta doble economía tiene la intención de explotar el capital simbólico de los artistas consolidados y acumularlo en los artistas nuevos. 


\section{Referencias}

ARTBO. (2017). [Homepage]. http://www.ARTBO.co/ Programa-ARTBO/Historia. Consultado el 22 de mayo de 2017

Barragán, P. (2008). The Art Fair Age. Charta.

Baudrillard, J. ([1972] 2002). Crítica de la Economía Política del Signo. Buenos Aires: Siglo XXI.

Bourdieu, P. (1979). La distinción: Criterio y bases sociales del gusto. Bogotá: Taurus. (1995). Las Reglas del Arte: Génesis y

Estructura del Campo Literario. Barcelona: Anagrama. (1997). Razones Prácticas sobre la Teoría de la Acción. Barcelona: Anagrama.

. (2003). El Amor al Arte: Los Museos Europeos y su Público. Barcelona: Paidos Ibérica.

Morgner, C. (2014a). The Evolution of the Art Fair. Historische Sozialforschung, 39(3), pp. 318-336.
. (2014b). The Art Fair as Network. The Journal of Arts Management, Law, and Society, 44(1), pp. 33-46. DOI: https://doi.org/10.1080/10632921.2013.872588

Rossi, A. (1993). La Arquitectura de la Ciudad. Barcelona: Ed. Gustavo Gili.

Salamanca, D. (16 de septiembre, 2015). Nada será como antes en ARTBO. Arcadia. Disponible en http:// www.revistaarcadia.com/arte/articulo/curaduriaARTBO-2015/44338. Consultado el 22 de mayo de 2017.

Simmel, G. (1991). The Berlin Trade Exhibition. Theory, Culture \& Society. 8, pp. 119-23. DOI: https://doi. org/10.1177/026327691008003008

Thornton, S. (2009). Seven Days in the Art World. W. W. Norton \& Company.

Walford, C. (1883). Fairs Past and Present: A Chapter in the History of Commerce. Londres: Elliot Stock.

White, H. (1981). Where do Markets come from? American Journal of Sociology. 87(3), pp. 517-547. 